This item was submitted to Loughborough's Research Repository by the author.

Items in Figshare are protected by copyright, with all rights reserved, unless otherwise indicated.

\title{
The relationship between energy and equity markets: evidence from volatility impulse response functions
}

PLEASE CITE THE PUBLISHED VERSION

http://dx.doi.org/10.1016/j.eneco.2014.01.009

\section{VERSION}

SMUR (Submitted Manuscript Under Review)

\section{PUBLISHER STATEMENT}

This work is made available according to the conditions of the Creative Commons Attribution-NonCommercialNoDerivatives 4.0 International (CC BY-NC-ND 4.0) licence. Full details of this licence are available at: https://creativecommons.org/licenses/by-nc-nd/4.0/

\section{LICENCE}

CC BY-NC-ND 4.0

\section{REPOSITORY RECORD}

Olson, Eric, Andrew J. Vivian, and Mark E. Wohar. 2019. "The Relationship Between Energy and Equity Markets: Evidence from Volatility Impulse Response Functions”. figshare. https://hdl.handle.net/2134/24284. 
The Relationship Between Energy and Equity Markets:

\title{
Evidence from Volatility Impulse Response Functions
}

\author{
Eric Olson \\ West Virginia University \\ Eric.olson@mail.wvu.edu \\ Andrew Vivian \\ Loughborough University \\ a.j.vivian@lboro.ac.uk \\ Mark E. Wohar \\ University of Nebraska-Omaha \\ mwohar@mail.unomaha.edu \\ and \\ Loughborough University
}

January 8, 2014

Key words: Volatility Impulse Response Functions, Dynamic Hedge Ratios, Volatility

Spillovers, Conditional Correlation, Commodity Market, Equity Index

JEL: C12, C32, G10, Q00 


\title{
The Relationship Between Energy and Equity Markets:
}

\section{Evidence from Volatility Impulse Response Functions}

\begin{abstract}
This paper examines the relationship between the energy and equity markets by estimating volatility impulse response functions from a multivariate BEKK model of the Goldman Sach's Energy index and the S\&P 500; in addition, we also calculate the time varying conditional correlations and time varying dynamic hedge ratios. From volatility impulse response functions, we find that low S\&P 500 returns cause substantial increases in the volatility of the energy index; however, we find only a weak response from S\&P 500 volatility to energy price shocks. Moreover, our dynamic hedge ratio anlysis suggests that the energy index is generally a poor hedging instrument.
\end{abstract}

Key words: Volatility Impulse Response Functions, Dynamic Hedge Ratios, Volatility

Spillovers, Conditional Correlation, Commodity Market, Equity Index

JEL: C12, C32, G10, Q00 


\section{INTRODUCTION}

Commodity markets are highly liquid and have a substantial proportion of investors who view commodities purely as Investments (financial assets / securities) rather than as a means to support "real" economic activity via hedging and risk management (Vivian and Wohar, 2012). The motivation behind including commodities in an investment portfolio is captured well by the promotional material listed on the website of PIMCO Commodity Real Return Strategy Fund,

"Because commodities are "real" assets like oil, metal or grain, they are sensitive to different economic factors and tend to perform differently, as evidenced by their low or negative correlation (tendency to move in tandem) with stocks and bonds. Adding commodities to a balanced portfolio may enhance overall diversification. Of course, diversification does not guarantee a profit or protect against loss. ${ }^{1}$,

As noted in Stoll and Whaley (2010), inclusion of commodities or commodity exchange traded funds as diversifying assets in traditional portfolios has become much more common since 1998. This increase in speculative market players who view commodities purely as an investment asset has been termed the "financialization" of commodities and is a departure from the traditional environment which primarily involved producers and consumers of the commodity.

Given this "financialization" of commodities, there is currently a debate over the role of speculative traders in commodity markets and whether they contribute to the rise of commodity prices since 2000. This position has been echoed by Michael Masters, George Soros, and more recently by former Congressman Joe Kennedy in a New York Times OpEd piece. ${ }^{2}$ Soros (2008) stated, "You have a generalized commodity bubble due to commodities having become an asset class that institutions use." In fact, the role of speculators in commodity markets was one of the most controversial aspects of the 2010 Dodd-Frank legislation; the legislation authorized the Commodity Futures Trading Commission (CTFC) the ability to limit trading in over-the-counter swaps. The CFTC used their new authority and voted on October $18^{\text {th }} 2011$ to limit positions in

\footnotetext{
${ }^{1}$ http://investments.pimco.com/Products/pages/287.aspx

${ }^{2}$ http://www.nytimes.com/2012/04/11/opinion/ban-pure-speculators-of-oil-futures.html
} 
28 physical commodity futures or financial equivalents. ${ }^{3}$ It should be noted that the "financialization" of commodities is pointed to as a partial explanation for the rise in correlations between commodities and equities during the financial crisis. However, this increase in correlations could also be partly due to global economic conditions impacting both the equity market and commodity market. While it is not the objective of the paper to provide formal evidence on this point, we do examine the impact of changing correlations for diversification and hedging. This paper importantly extends prior literature by examining volatility impulse responses to equity return shocks and to energy return shocks.

There is growing evidence that equity and commodity markets are inter-connected and that the correlations between commodities and equities has increased since the early 2000s (see for example Silvennoinen and Thorp, 2013; Creti, Joets, and Mignon, 2013; Gilbert, 2010). This evidence is cited to support the assertion that speculators have had a significant effect on commodity prices since the early 2000s, although whether speculators have had a material impact on the properties of commodity time series is disputed (Valiant, 2011; Hamilton and $\mathrm{Wu}$, 2012; Vivian and Wohar, 2012). In fact, the correlation between energy commodities and equities may not be driven by the "financialization" of commodities but rather may reflect other factors. For example, it is plausible global economic conditions play a major role. The deterioration in global economic conditions could have been an important contributing factor to the spike in correlations between the stock market and energy prices during 2008-9 when stock market falls accompanied energy price falls. Regardless of the reason, if the correlation between traditional asset classes and commodities has increased, then the usefulness of commodities as a

\footnotetext{
${ }^{3}$ The commodities include contracts for corn, wheat, soybeans, oats, cotton, oil, heating oil, gasoline, cocoa, milk, sugar, silver, palladium and platinum.
} 
diversification tool (as suggested in the above PIMCO material) has become much more limited. ${ }^{4}$ However, much prior literature appears to have overlooked the fact that increased correlations will actually make commodities a better hedge for equity (provided the absolute value of the correlation coefficient increases). Given that hedging typically involves taking a long position in one asset (here equity) and a short position in another asset (here a commodity), the rise in correlations suggests that a move in equity price will be better offset by a short position in the commodity; thus, the hedge has become more effective. Nevertheless, the relationship between commodities and equities is certainly a pertinent question that attracts attention from policymakers, producers, academics, investors, the media and consumers.

Creti, Joets, and Mignon (2013) note that "volatility of commodity prices is thus a central issue for the world economy, as notably illustrated by the G20 which addressed the question of excessive fluctuations and volatility of commodity prices in its September 2009 Pittsburgh summit" (p16). This begs the questions of i) How quickly does a volatility shock dissipate and ii) What is the response of commodity volatility to a shock to equity volatility (or vice-versa)? To our knowledge these questions have not yet been examined using volatility impulse response functions in the equity-energy market context. An important contribution of this paper is to fill this gap in the literature. We meet this objective by estimating volatility impulse response functions from a multivariate BEKK model of the Goldman Sach's Energy index and the S\&P 500; in addition, we also calculate the time varying conditional correlations and time varying dynamic hedge ratios. We focus on the Energy index since it is a widely used benchmark for investment performance in the energy commodity market; ${ }^{5}$ it is consequently a useful overall barometer for the energy market. To generate the volatility impulse response functions, we

\footnotetext{
${ }_{5}^{4}$ If the correlation has unexpectedly increased then the benefits of diversification will be smaller than originally anticipated.

${ }^{5} \mathrm{http}$ ///us.spindices.com/indices/commodities/sp-gsci-energy
} 
employ the methodology outlined in Hafner and Herwartz (2006). One benefit of their methodological approach is that it allows one to pick "shocks" from a specific time period. As such, we utilize this feature to examine how the variance of each of variable (energy index, S\&P 500 index) respond to "low", "median", and "high" shocks. Put another way, we are able to show how the variance of the S\&P 500 (energy index) responds to small and large price shocks in the energy (S\&P 500) sector.

To preview our results, first, we find that low S\&P 500 returns cause substantial increases in the volatility of the energy index; however, we do not find any substantial effects on the volatility of the S\&P 500 that result from large positive energy price returns. Secondly, we find that the conditional correlation increased substantially during the financial crisis (2008-2010) but was approximately zero beforehand; this is broadly consistent with Creti et al.'s (2013) finding for Oil and S\&P500 using an alternative modelling approach. Thirdly, the analysis of dynamic hedge ratios suggests that the energy index is a poor hedging instrument for equity movements, apart from during the financial crisis (2008-2010). Consequently our evidence suggests that the impact of financial crisis had a differing impact depending upon whether the market participant was looking to diversify an investment portfolio or hedge an equity position. For a speculative investor attempting to achieve diversification benefits by using the energy index during the crisis will have found these were much smaller when they were needed most; in contrast the usefulness of the energy index to hedge equity movements greatly increased during the financial crisis.

The remainder of this paper is organized as follows. Section 2 summarizes recent literature. Section 3 discusses our data and methodology. Section 4 presents our model results and evaluates the time-varying conditional correlations and time varying hedge ratios. Section 5 concludes. 


\section{LITERATURE REVIEW}

A number of studies have investigated the effects of energy price changes on real economic variables since the 1970s oil price shocks (Hamilton, 1983, 2003; Kilian, 2008; and references therein). It is generally shown that oil price changes significantly affect economic activity for various developed and emerging countries. In contrast, the strand of research on the potential links between oil prices and stock markets has gained ground only recently, and its focus is essentially on broad market indices. The study by Jones and Kaul (1996) is amongst the first to examine the reaction of stock markets to oil shocks and finds that changes in stock prices can be partially accounted for by the effect of oil price movements on current and future cash flows.

A large body of subsequent literature confirm significant responses of stock returns to oil shocks using a wide range of different econometric techniques including vector autoregressive (VAR) models (Huang et al., 1996; Sadorsky, 1999; Apergis and Miller, 2009; Fayyad and Daly, 2011; Park and Ratti, 2008), cointegration (Sadorsky, 1999; Park and Ratti, 2008), and vector error-correction models (VECM) (Apergis and Miller, 2009). Apergis and Miller (2009) also note that while the effect of oil shocks on stock prices are statistically significant they are of small magnitude. Fayyad and Daly (2011) emphasise that during the global financial crisis period i) the predictive power of oil for stock returns increased and ii) stock returns become more sensitive to oil shocks. Huang et al. (1996) find that oil prices only affect the stock market returns of energy companies; the effect is i) the lead length is one day and ii) the economic significance is limited given potential profits cannot cover trading costs. Park and Ratti (2008) compare the effects of world oil price shocks and national oil price shocks, interestingly they 
find that world oil price shocks have stronger effects than national shocks. Park and Ratti's (2008) evidence also suggests that the oil prices shocks are incorporated into stock prices within a month. Sadorsky (1999) reports that oil price shocks depress real stock returns; in contrast real stock returns shocks do not impact oil prices but do affect interest rates and industrial production. Wang, Wu, and Yang (2013) examine the linkage between oil price shocks and stock market returns for oil importing and exporting countries; two of their key findings are i) oil price shocks are able to explain more of the variation in stock returns for oil exporting countries and ii) oil demand uncertainty can have significant effects on oil exporters equity index that persists for more than six months but just a temporary impact on oil importers equity index. For emerging economies the evidence of the impact of oil on stock markets is mixed. Maghyereh (2004) finds that oil shocks have no significant impact on stock index returns in 22 emerging economies; however, Basher and Sadorsky (2006) finds strong evidence that oil price risk has a significant impact on stock price returns in emerging markets.

There is also a growing body of literature that examines if commodities are useful for diversification of an investment portfolio (see for example Jenson, Johnson and Mercer, 2000; Erb and Harvey, 2006; Gorton and Rouwenhorst, 2006). Jenson, Johnson and Mercer (2000) consider the mean-variance optimizing investor and find (s)he would place a substantial weight on commodities in a multi-asset portfolio comprising stocks, bonds, T-Bills and real estate; they find portfolio returns are increased when commodities are included, regardless of the level of risk. Jenson, Johnson and Mercer (2000) also highlight that the weight on commodities is higher during restrictive monetary policy conditions. Gorton and Rouwenhorst (2006) emphasise that commodities and equities fluctuate in different ways over the business cycle. Erb and Harvey (2006) report that correlations within the commodity market tend to be very low; hence they 
suggest an equally weighted portfolio of commodities can offer large diversification benefits. They also find there can be gains from momentum based strategies and from exploiting information in the term structure of commodities; these have been further substantiated by Fuertes, Miffre and Rallis (2010). Overall, Erb and Harvey (2006) suggest that a portfolio of commodities can offer return and risk characteristics similar to equities.

Much of the academic literature that investigates the energy-equity return relationship, focuses on spillovers between the oil market and the equity market (see, for example, Sadorsky (2004), Hammoudeh and Aleisa (2002), Tansuchat, Chang, and McAleer (2010)). ${ }^{6}$ Arouri, Lahiani, Nguyen (2011) find substantial return and volatility spillovers from oil to stock returns in the Gulf Cooperation Council Countries using a VAR-GARCH approach. Arouri, Jouini, and Nguyen (2012) investigate volatility spillovers between oil price fluctuations and seven European sector stock returns using a VAR-GARCH approach; they find i) more evidence of spillovers from oil to equity sector returns and ii) optimal portfolio weights and hedge ratios vary substantially across different equity sectors.

Jacobsen, Marshall, and Visaltanachoti (2008) and Jahan-Parvar, Vivian and Wohar (2012) provide evidence of in-sample return predictability from commodities to equities. Valiant (2011) and Hamilton and $\mathrm{Wu}$ (2012) examine the role speculators have played in commodity markets and find that speculators and index funds have had a limited impact. Büyüksahin, Haigh and Robe (2008) find that equity and commodity index returns have not become more correlated over the 1991-2008 period. Mollick and Assefa (2013) investigate the linkage between US stock returns and Oil prices in the US during the financial crises period 2008-2009. Most recently,

\footnotetext{
${ }^{6}$ For linkage between oil prices and stock returns, see also Jones and Kaul (1996), Hammoudeh, et al. (2004), Park and Ratti (2008), Chiou and Lee (2009), Malik and Ewing (2009), Choi and Hammoudeh (2010), and Filis et al. (2011). Recent studies investigating transmission between the oil market and equity markets include Arouri and Rault (2012), Awartani and Maghyereh (2013) and Akoum, Graham, Kivihaho, Nikkinen, and Omran (2012), Arouri, Jouini, and Nguyen (2012).
} 
Mensi, Beljid, Boubaker, and Managi (2013) employ a VAR-GARCH model to investigate the return links and volatility transmission between the S\&P 500 and the commodity price indices for energy, food, gold and beverages over the period 2000-2011. They find evidence of volatility spillovers both from S\&P 500 to each commodity index and from almost every commodity index to the S\&P500. They also suggest that using a commodity index to diversify an equity investment can improve its overall risk-adjusted performance and that oil and precious metals are more costly hedges of equity than wheat or beverages.

Estimation of multivariate GARCH models is often difficult in that convergence is not always achieved due to the high number of parameters estimated. Moreover, models in which correlations are time-varying are more difficult to estimate than the constant conditional correlation models which are easier to estimate than many of their counterparts and their parameters (correlations) have a natural interpretation (Silvennoinen and Terasvirta, 2009). ${ }^{7}$ Primiceri (2005), notes that time-varying correlation models can uncover novel and substantial insights between economic variables. Engle (2002) proposed a GARCH model that incorporates dynamic conditional correlations which has been widely implemented in numerous subsequent studies. One important advantage of time varying conditional correlations with regards to financial variables is that it allows one to determine whether and how much hedge ratios and portfolio allocations change over time. Asai, McAleer and Yu (2006) and Bauwens, Laurent and Rombouts (2006) provide reviews that cover the issue of conditional correlation in GARCH models.

However, multivariate GARCH models do offer substantial insights. Hammoudeh et al. (2004) find two-way interactions between the S\&P Oil Composite index, and oil spot and futures

\footnotetext{
${ }^{7}$ The interest in investigating time-varying correlation has almost been employed in the area of time-varying structural vector autoregressions applied to monetary policy (see Primiceri, 2005).
} 
prices. Agren (2006) presents strong evidence of volatility spillovers from oil prices to stock markets using the asymmetric BEKK model for Japan, Norway, UK and US stock markets. Malik and Hammoudeh (2007) find that Gulf equity markets receive volatility from the oil markets, but only in the case of Saudi Arabia is the volatility spillover from the Saudi market to the oil market significant, underlining the major role that Saudi Arabia plays in the global oil market. Finally, using a two-regime Markov-switching EGARCH model, Aloui and Jammazi (2009) examines the relationship between crude oil shocks and stock markets from December 1987 to January 2007 and finds that net oil price increases plays a significant role in determining both the volatility of real returns and the probability of transition across regimes. Finally, Tansuchat, Chang, and McAleer (2010) estimate a variety of multivariate conditional volatility models and find significant interactions in the volatilities between crude oil returns and stock index returns.

Three very recent papers examine correlations between equities and commodities (Silvennoinen and Thorp, 2013, Creti, Joets, and Mignon, 2013, and Mensi, Beljid, Boubaker and Managi, 2013). Silvennoinen and Thorp (2013) examine the relationship between commodity futures and equity returns. They find that equity volatility (VIX) and open interest of futures are important determinants of conditional volatility and of state changes in the correlation between equity returns and commodity futures returns. In contrast to Silvennoinen and Thorp, our model allows for (1) variable spillovers in the mean and variance equations and (2) the correlations between the variables to exhibit much greater time-variation. ${ }^{8}$ More recent work allowing for correlations to change over time has been conducted by Creti, Joets, and Mignon (2013). They investigate the links between price returns of 25 commodities and stocks over the

\footnotetext{
${ }^{8}$ Silvennoinen and Thorp's (2013) model delivers essentially constant correlations within regimes but allows the correlations to change depending upon the regime.
} 
period January 2001 to November 2011. They employ a DCC-GARCH methodology and find that the correlations between the returns of commodities and the equity market return evolve through time and are highly volatile. Creti, Joets, and Mignon (2013) also highlight the the 2007-2008 financial crisis period to emphasize the strong links between commodities and equity markets following the financialization of commodity markets. ${ }^{9} \quad$ Finally, Mensi et al. (2013) examine (unconditional) correlations and spillovers between commodity indices and the S\&P500 over the period 2000-2011. Their results indicate there are spillovers between several commodity indices and the S\&P500. Compared to Mensi et al. (1) we explore in more detail the time varying correlations between energy and the S\&P500, which they do not emphasize, (2) we use weekly data, which ameliorates concerns over non-synchronicities in daily data. Further, in contrast to all three of these very recent papers we examine volatility impulse response functions (VIRFs).

Sadorsky (2000) investigates the linkage between energy future prices and exchange rates. They find that futures prices for crude oil, heating oil, and unleaded gasoline, are cointegrated with a trade weighted index of exchange rates. Using Granger causality tests they find that exchange rates preceded movements in heating oil futures prices in the short-run and the long-run. They also find that movements in exchange rates preceded movements in crude oil futures prices in the short-run. In a more recent paper Basher, Haug, and Sadorsky (2012) employ a six variable structural VAR and impulse response analysis to analyze the dynamic relationship between oil prices, exchange rates, and emerging market stock prices. They find that positive shocks to oil prices lead to depressed emerging stock prices and US dollar exchange rate depreciation in the short-run. They argue that rising oil prices will generate a current account surplus for oil exporters and a current account deficit for oil importers. The long-run

\footnotetext{
${ }^{9}$ However, the cause of the strong links between equities and commodities during the financial crisis is debated.
} 
expectations is that the oil importers will experience a depreciation of the currencies because of the adverse terms of trade effect and this expectation of future depreciation in the value of the dollar on the short-run. They find no evidence that oil prices respond to exchange rate shocks.

This study identifies three main areas that have been relatively under-researched. Firstly and most importantly, to our knowledge, prior literature examining energy-equity returns linkages has not examined volatility impulse response functions; therefore it is not known how quickly energy volatility moves to its expected value following an equity shock (or vice-versa). ${ }^{10}$ In particular, the response to extreme shocks has not been examined in detail. Secondly, prior literature does not tend to place much emphasis on the impact of currency returns upon the energy-equity relationship even though equity and energy futures contracts denominated in dollars would share "dollar" shocks we model this directly by including the dollar index in our model. Our primary reason for including the dollar index was because energy commodities and shares of the S\&P 500 are denominated in dollars. ${ }^{11}$ As such, we were attempting to capture any shocks to the denominating currency. Thirdly, prior literature tends to overlook time-variation in the hedge ratio between energy and equity index. To meet these objectives we employ a multivariate-GARCH model that allows for time varying correlations and cross-market spillover effects between energy and S\&P 500 returns as well as variances while controlling for dollar effects in the mean and variance equations. This is discussed in more detail in section 3 below. We then present results for dynamic conditional correlations, dynamic hedge ratios and volatility impulse response functions from the multivariate-GARCH model.

\footnotetext{
${ }^{10}$ Volatility impulse response functions dealing with return linkages between energy (oil) and other agricultural commodities have been examined in the recent work of Nazlioglu et al. (2013). This focuses on a 1 standard deviation shock to oil; in contrast we examine the volatility response to low $\left(5^{\text {th }}\right.$ percentile $)$, median and high $\left(95^{\text {th }}\right.$ percentile $)$ return shocks.

${ }^{11}$ It should be noted that prior literature on oil-equity volatility spillovers tends not to include additional explanatory variables at all (see for example, Arouri et al., 2011, 2012; Mensi et al., 2013). We investigate one potentially important variable the dollar index, however, further research could investigate other potentially important variables such as the short-term interest rate (Frankel, 2014).
} 


\section{DATA AND METHODOLOGY}

Our empirical analysis is based upon weekly data taken from Thomson's Datastream. ${ }^{12}$ The sample period is from January $1^{\text {st }} 1985$ to April $24^{\text {th }} 2013$. This period covers the early 1990s global recession, the more recent financial crisis as well as periods of economic growth. The S\&P 500 spot index return is used to proxy the US equity market. As a proxy for the energy sector, we use the Goldman Sachs Energy Excess Return Index; this is based on a long-only investment in commodity futures and index components are capitalization weighted. The Energy index is a barometer for the whole energy sector and a widely used benchmark for investment performance. It is also the case that the US energy market has become more diversified with (natural) gas and renewables now being an important component of the market, although oil remains the single most important commodity. ${ }^{13}$ Assuming energy and equities follow a martingale process, than the relationship between the two assets will primarily be determined by the correlation of their stochastic components. Put another way, if there is a common shock affecting both assets, then the correlation will be positive. For example, the most obvious shock that each (energy return and the S\&P 500 return) would share is shocks to the dollar simply because that is the currency that each are denominated in. Thus, in time periods when market participants unexpectedly demand dollars or dollar denominated assets, the correlation between all dollar denominated assets will be positive.

\footnotetext{
${ }^{12}$ Weekly data substantially reduces any issues relating to non-synchronicity. Even in the US stock markets and commodity markets generally close at different times.

${ }^{13}$ Hamilton (1983) points out that Oil shocks tend to precede economic downturns and Oil shocks also tend to have an adverse impact on equity markets also; which might help explain the why oil and equity linkages has been so thoroughly examined. However, now other energy commodities are of non-negligible size and hence we consider the energy market as a whole in our analysis.
} 
Multivariate volatility GARCH models such as BEKK (full parameterization), CCC (constant conditional correlation), DCC (dynamic conditional correlation) models with dynamic conditional covariances and conditional correlations can be used for more examples than can univariate model. Four common GARCH specifications have been employed in modeling volatility dynamics between asset markets (BEKK, diagonal, constant conditional correlation, and dynamic conditional correlation). The diagonal, the CCC and the DCC model are simpler can be estimated in two-steps. In the first step univariate GARCH models are used to estimate variances. In the second step correlations are model based on the standardized residuals from step 1. The econometric specification used in this paper has two components. First, a VAR with one lag to allow for autocorrelations and cross-correlations. Second, a multivariate GARCH model is then used to model the time-varying variances and covariances. In this paper we employ the more complex BEKK specification in order to compute volatility impulse response functions.

We specify the mean equation for the system by the following:

$$
Y_{t}=\mathbf{c}+\mathbf{A} Y_{\mathrm{t}-1}+\mathbf{B} \text { dollar }_{t-1}+\mathbf{v}_{t}
$$

where $Y_{t}=\left(R_{t}^{\text {Energy }}, R_{t}^{S \& P 500}\right)^{\prime} \cdot \mathrm{R}_{\mathrm{i}, \mathrm{t}}$ is the weekly return of the Goldman Sachs energy index and the S\&P 500 respectively, and dollar is the weekly return of the dollar index index. ${ }^{14} \mathbf{A}, \mathbf{B}$, and $\mathbf{c}$ are $n \times n$ coefficient matrices. $\mathbf{v}_{t}=\left(\varepsilon_{t}^{E n e r g y}, \varepsilon_{t}^{S \& P 500}\right)^{\prime}$ that contain the residuals from the mean equations in (1), such that each residual,

$$
\varepsilon_{t}=h_{t}^{\frac{1}{2}} \eta_{t}
$$

\footnotetext{
${ }^{14}$ We use the weekly return in the Trade Weighted U.S. dollar index: Major currencies from the St. Louis Fred database.
} 
and each innovation $\eta_{i, t}$ is an i.i.d. random shock. Thus, (1) and (2) is simply a bivariate VAR-

GARCH model of the S\&P 500 and the energy commodity index with the dollar index as an independent variable.

We follow Engle and Kroner (1995) and use the BEKK ${ }^{15}$ specification to model the conditional variances but we again include the dollar as an independent variable:

$$
\mathbf{H}(t)=\mathbf{C}^{\prime} \mathbf{C}+\mathbf{A}^{\prime} \mathbf{u}(t-1) \mathbf{u}^{\prime}(t-1) \mathbf{A}+\mathbf{B}^{\prime} \mathbf{H}(t-1) \mathbf{B}+\mathbf{D}^{\prime} \operatorname{dollar}(t-1) \mathbf{D}
$$

where $\mathrm{C}$ and $\mathrm{D}$ are lower triangular matrices and $\mathrm{A}$ and $\mathrm{B}$ are general $n \times n$ matrices. Thus, each term is positive semi-definite by construction. From (3) the conditional variance for the Energy and S\&P 500 returns is determined by past shocks and past conditional variances of the S\&P 500 return and Energy return and the dollar index. ${ }^{16}$ Thus, if one carries out the above matrix multiplications, the conditional variance of the energy index would be $h_{11 t}=\left(c_{11}^{2}+c_{12}^{2}\right)+\left(d_{11}^{2}+d_{12}^{2}\right)$ dollar $r_{t-1}+b_{11}^{2} h_{11, t-1}+2 b_{11} b_{21} h_{12, t-1}+b_{21}^{2} h_{22, t-1}+\alpha_{11}^{2} \varepsilon_{1, t-1}^{2}+2 \alpha_{11} \alpha_{21} \varepsilon_{1, t-1} \varepsilon_{2, t-1}+\alpha_{21}^{2} \varepsilon_{2, t-1}^{2}$ Thus, it is important to note that by including the dollar as covariate in the conditional variance equations, we are conditioning the correlations between the energy index and the S\&P 500 on the dollar.

In addition, we also follow Kroner and Sultan (1993) and Mensi et al. (2013) and calculate hedge ratio for the S\&P 500 and each commodity index using the estimated conditional

\footnotetext{
${ }^{15}$ Other Multivariate models exist, such as CCC, DCC, or VARGARCH. We chose the BEKK model primarily because in order to implement the VIRF the multivariate Garch model must be able to be transformed into a multivariate VECH model which the BEKK model accommodates.

${ }^{16}$ We also attempted to estimate a tri-variate GARCH model with a dollar return variance equation. We could not obtain convergence. This is not surprising as adding an extra variable results in the addition of a large number of parameters that must be estimated.
} 
co variances. That is, in order to minimize the risk that is $\$ 1$ long the S\&P 500, the investor should short $\$ \beta$ of the commodity indices. Thus, the hedge ratio is then

$$
\beta_{t}^{\text {energy, } S \& P 500}=\frac{h_{t}^{\text {energy }, S \& P 500}}{h_{t}^{\text {energy }}}
$$

However, in contrast to Mensi et al. (2013), we report the time-varying hedge ratios, which reflect changes in the conditional covariance and conditional variances of the series. If commodities are true hedges one would want the hedge ratios to stay relatively constant over the estimated time period. As noted above, it is important to control for the dollar given that the hedge ratios are calculated using conditional covariances.

\subsection{Variance Impulse Response Functions}

In order to visually examine the volatility spillovers, we employ Hafner and Herwartz's (2006) methodology and generate volatility impulse response functions (VIRF) for the above estimated model. As such, we first transform the above BEKK model into its vech representation. In a standard impulse response VAR framework, a shock is defined as any nonzero $u_{t}$. As such, one is then able to examine how the non-zero shocks affect each of the variables in the system by examining how the forecast of each variable changes given the shock. Hafner and Herwartz (2006) define a volatility impulse response function as the expectation of volatility conditional upon a specific shock and history minus the expectation conditional only upon history. That is,

$$
\begin{gathered}
\operatorname{vech}\left(V_{t+1}\right)=\mathbf{A} \operatorname{vech}\left(u_{t} u_{t}^{\prime}-\mathbf{H}_{t}\right) \\
\operatorname{vech}\left(V_{t+k}\right)=(\mathbf{A}+\mathbf{B}) \operatorname{vech}\left(V_{t+k-1}\right)
\end{gathered}
$$


where $\mathbf{H}_{\mathbf{t}}$ is the estimated covariance matrix that was estimated above. The shock to the variance is the amount that $u_{t} u_{t}^{\prime}$ differs from its expected value. Thus, obviously one must then select $u_{t} u_{t}^{\prime}$. Because Hafner and Herwartz (2006) use exchange rate data, they select $u_{t} u_{t}^{\prime}$ from two well known historical episodes. They select the $u_{t} u_{t}^{\prime}$ from "Black Wednesday", which was the day the lira and the pound left the European exchange rate mechanism (ERM), and the $u_{t} u_{t}^{\prime}$ from August 2, 1993 which was the date the European community enlarged the bands of the ERM.

We take a different approach in selecting the specific $u_{t} u_{t}^{\prime}$. Rather than ad hocly selecting dates, we select the $u_{t} u_{t}^{\prime}$ based upon the distribution of the S\&P 500 and energy returns. That is, we first estimate the above model. We then order the S\&P 500 and energy

commodity returns and record the dates that correspond to the $5^{\text {th }}$ percentile, median, and $95^{\text {th }}$ percentile of each distribution. We subsequently select the estimated $u_{t} u_{t}^{\prime}$ 's that correspond to the recorded dates. We then implement Hafner and Herwartz's (2006) methodology and generate volatility impulse responses for each of the $u_{t} u_{t}^{\prime} \mathrm{s}$. Thus, we are able to generate volatility impulse response functions that correspond to low, medium, and high shocks for each variable.

\section{EMPIRICAL RESULTS}

\subsection{Mean and Variance Equation Estimates}

Panel A of Table 1 present estimation results for the mean equations. The lagged dollar return is the only variable that is significant in the energy return equation. In the S\&P 500 mean return equation, both the lagged S\&P 500 return and the lagged dollar return enter with a negative but significant coefficient. In the variance equations (Panel B of Table 1), note that because of the squared structure of the BEKK model, the negative coefficients of the matrices 
imply that the variance is affected more when the shocks move in opposite directions. ${ }^{17}$ The lagged dollar return is negative and statistically significant in the energy return variance equation but insignificant in the S\&P 500 return variance. Both energy returns and S\&P 500 returns display low short-term volatility persistence as evidenced by the lagged volatility coefficient. In contrast, conditional volatility is highly persistent both for energy and S\&P 500.

\subsection{Time Varying Correlations and Hedge Ratios}

One advantage of the empirical approach adopted in this paper is that it enables the conditional correlation between the assets to change continuously. There is a large literature suggesting that asset correlations are related to economic conditions, for example equity-bond correlations fall during periods of high equity market uncertainty (Connolly, Stivers and Sun, 2007) but correlations of international stock markets increase during bad times (Ribeiro and Veronesi, 2002). ${ }^{18}$ Obviously, diversification benefits from investing in different asset classes fluctuate if correlations between asset classes change depending on the macroeconomic environment. The conditional correlation graph (Figure 1) illustrate that there is substantial time variation in the relationship between equity and energy returns. For the energy index there is clear evidence of a spike in correlation around 2008-2009. It appears as though this is a temporary shock as the correlation returns to zero over time. There is a spike in the correlation coefficient around the end of 2008 and beginning of 2009. The high correlation of energy lasted until the beginning of 2011; hence it is unclear whether energy-equity correlations have permanently increased following the financial crisis. However, there is very limited evidence of an increase in correlations prior to the financial crisis period, even though speculative investors

\footnotetext{
${ }^{17}$ The off-diagonal coefficients should not be interpreted in the same way as a traditional GARCH model because of the squared nature of the BEKK model. The impulse response functions are much more informative in this context. We take these up in later sections.

${ }^{18}$ Connoly, Stivers and Sun (2007) measure of change in implied volatility can be interpreted as uncertainty.
} 
had substantially increased and were a major part of the market since at least 2005 (see for example Doyle, Hill and Jack, 2007).

Figure 2 reports the time varying hedge ratios. Until 2008 this ratio fluctuated around zero. After 2008 these ratios are persistently above zero. As noted above, these ratios state the short position one should take in energy to reduce the variance of a portfolio containing just equity. ${ }^{19}$ Given the erratic nature of the hedge ratios in Figure 2, using energy indices as a hedging instrument for equities is obviously questionable. However, our results are consistent with Gorton and Rouwenhorst (2006) who present some evidence that the correlation between the equity index and commodity index futures varies over time. ${ }^{20}$ In addition, we find substantial variability of the hedge ratio due to the time varying correlation between the energy and equity indices; this variability of hedge ratio greatly inhibits its practical usefulness since it indicates the hedge requires frequent and large adjustments which would be costly.

Overall, we observe there is little discernible pattern (or trend) for the hedge ratio, in general, until the recent financial crisis period. There is widespread evidence of an upward spike in hedge ratio during the financial crisis period around 2008-2009; the increased hedge ratio (and increased correlation) indicates that the short position in the energy index is better able to offset movements from a long position in equity market. Hence, this suggests that energy became a much better hedge for equities during this extremely bad period. This new evidence suggests that hedging benefits from using commodities are increased during extreme downturns. In contrast, the diversification benefits from commodities are reduced when correlation increases; this is

\footnotetext{
${ }^{19}$ Note that if the hedge ratio is negative then a long position in energy is required.

${ }^{20}$ Gorton and Rouwenhorst (2006) find the correlation equity index and commodity future index depends importantly on the phase of the economic cycle and also depends on the holding period.
} 
because when considering diversification the investor is assumed to have a long position in both the equity index and the energy index.

\subsection{Volatility Impulse Response Functions}

Figures 3-4 displays the volatility impulse response functions over a 100 day horizon. Each column specifies the percentile shock on each of the estimated co-variances which are listed by row. As noted above, we select the $u_{t} u_{t}^{\prime}$ based upon the distribution of the energy and S\&P 500 returns. In figure 3, we estimate the model in equations (1) to (3) and then order the energy returns and record the dates that correspond to the $5^{\text {th }}$ percentile, median, and $95^{\text {th }}$ percentile. We subsequently select the estimated $u_{t} u_{t}^{\prime}$ 's that correspond to the recorded dates (Figure 3). In a similar fashion we do the same thing for the S\&P 500 returns (Figure 4). We then implement Hafner and Herwartz's (2006) methodology and generate volatility impulse responses for each of the $u_{t} u_{t}^{\prime}$ s. Thus, we are able to generate volatility impulse response functions that correspond to low, medium, and high returns for each variable.

First, note in the top row in Figure 3 a shock from the $5^{\text {th }}$ percentile as well as the median returns, results in an initial variance (response) that is two and one-half times the expected conditional variance, whereas a shock to $95^{\text {th }}$ percentile shock results in an initial increase in energy return variance which is approximately five times higher than expected. However, regardless of the shock, the energy variance dissipates back to its expected value (the horizontal line at 0.0 ) after 100 days. Interestingly, note that in the bottom row of Figure 3, energy shocks do not substantially (all less than one) alter the expected variance of the S\&P 500. In fact, a 
median energy shock does not alter the expected conditional variance of the S\&P 500 at all. Overall, the response of S\&P 500 volatility to energy return shocks is rather muted.

Figure 4 examines responses to shocks of equity returns. Note that in the bottom row of Figure 4 a shock from the $5^{\text {th }}$ percentile results in a S\&P 500 conditional variance that is approximate one times greater than expected whereas a median return shock results in an S\&P 500 variance that is not different than expected. A $95^{\text {th }}$ percentile shock, results in an increase in the S\&P 500 return variance that is approximately two times higher than expected. The S\&P 500 variance does dissipate back to its expected value following return shocks; in particular the $95^{\text {th }}$ percentile shock dissipates more quickly than the $5^{\text {th }}$ percentile shock. In contrast to Figure 3, notice in the top row of Figure 4, that there is a substantial cross-asset effect; in figure 4 we find that the volatility of energy is greatly influenced by the S\&P 500. The $5^{\text {th }}$ percentile S\&P 500 return, results in an increase in the energy variance that is ten times greater than expected. Note that the lower $5^{\text {th }}$ percentile of the S\&P 500 results in the greatest spillover on the energy index variance for the VIRF. It is three times larger than the corresponding $95^{\text {th }}$ percent value. Hence there is an asymmetry in the volatility response to for the $5^{\text {th }}$ and $95^{\text {th }}$ percentile of S\&P 500 returns (Figure 4 top row). Our results suggest that energy sector volatility is most sensitive to low S\&P 500 returns; however, in contrast S\&P 500 volatility is weakly related to energy return shocks. This is particularly interesting given that much prior literature emphasizes spillovers from energy to equity markets (see for example Arouri, Jouini and Nguyen, 2012; Agren, 2006; Malik and Hammoudeh, 2007). Nonetheless, our VIRF results of strong responses of energy volatility to equity shocks also appear consistent with some recent analyses of energy volatility. Mensi, Beljid, Boubaker, and Managi (2013) that find that past shocks and volatility of the S\&P 
500 spillover to the oil markets and Silvennoinen and Thorp's (2013) report that equity market (implied) volatility is a significant determinant of energy commodity volatility.

Most of the earlier literature investigates linkages between energy returns and equity returns rather than their volatility. While the linkage between oil returns to equity returns has been explained through a number of stories, the reverse is not true. One plausible reason for the transmission of volatility that emanates from the stock market to the energy market is that equity market volatility could reflect higher risk facing investors in general. Thus, it will also affect energy markets if speculative investors are active in both energy and equity markets. Secondly, equity markets, which are strongly forward looking, could be an earlier indicator of economic risk than the energy markets (Soucek and Todorova, 2013 p597); this would suggest equity volatility leads energy volatility consistent with our VIRF finding of a strong response of energy volatility to equity return shocks. It is also possible that controlling for exchange rate changes in our analysis contributes to our findings given that Sadorsky (2000, p253) finds "exchange rates transmit exogenous shocks to energy futures prices."

\section{CONCLUSION}

This paper uses volatility impulse response functions, conditional correlations, and dynamic hedge ratios to examine the relationship between the energy sector and the S\&P 500 . Our volatility impulse response functions suggest that the volatility of energy is much more sensitive to low S\&P 500 returns. In addition, it appears that the conditional variance of energy is particularly sensitive to low S\&P 500 returns/news. This could reflect that the equity market is an earlier indicator of economic risk than the energy market (Soucek and Todorova, 2013 p597); in particular the S\&P 500 should drop dramatically (have a low return shock) when high 
economic uncertainty is anticipated. Our finding that energy volatility is sensitive to equity return shocks is of considerable interest given that much prior literature emphasizes spillovers in the other direction from energy market to equity market (see for example Arouri, Jouini and Nguyen, 2012; Agren, 2006; Malik and Hammoudeh, 2007).

In this paper we examine both time-varying conditional correlations and time-varying hedge ratios. Our results do not support the notion that the increased correlation between the energy and S\&P 500 was the result of speculation; conditional correlations are not substantially different during the periods in which the "financialization" of energy commodities occurred. However, during the financial crisis period both the conditional correlation and hedge ratios increased markedly. While both these measures are closely connected their implications depend upon the type of commodity market participant considered. For a speculative investor pursuing a diversification strategy by investing in the energy index, the increased correlation will have shrunk the benefit from diversification when they were most needed. In contrast for a hedger, the increased hedge ratio (and increased correlation) indicates that the short position in the energy index is better able to offset movements from a long position in equity market. However except for the financial crisis period, equity-energy correlations were typically low but with substantial variability; this casts doubt upon the general use of energy as a good hedging instrument for the S\&P 500. 


\section{BIBLIOGRAPHY}

Agren, M., 2006. Does oil price uncertainty transmit to stock market? Working Paper 23, Uppsala University.

Akoum, I., Graham, M., Kivihaho, J., Nikkinen, J. and Omran, M. (2012). Co-movement of oil and stock prices in the GCC region: A wavelet analysis, The Quarterly Review of Economics and Finance, 52, 385-394.

Aloui, C. and R. Jammazi. 2009, The effects of crude oil shocks on stock market shifts behavior: A regime switching approach, Energy Economics, 31, 789-799.

Apergis, N., Miller, S.M., 2009. Do structural oil-market shocks affect stock prices? Energy Economics 31, 569-575.

Arouri, M., Lahiani, A. Nguyen, D.K., 2011. Return and Volatility Transmission Between World Oil Prices and Stock Markets of the GCC Countries, Economic Modeling, 28, 1815-1825.

Arouri, M., Jouini, J. Nguyen, D.K., 2012. On the Impact of Oil Price Fluctuations on European Equity Markets: Volatility Spillover and Hedging Effectiveness, Energy Economics, 34, 611-617.

Arouri, M. and Rault, C. (2012). Oil prices and stock markets in GCC countries: Empirical evidence from panel analysis, International Journal of Finance and Economics, 17, 242253.

Asai, M., McAleer, M. and Yu, J. (2006). Multivariate stochastic volatility: A review, Econometric Reviews, 25, 145-175.

Awartani, B. and Maghyereh, A. (2013). Dynamic spillovers between oil and stock markets in the Gulf Cooperation Council Countries, Energy Economics, 36, 28-42.

Basher, S.A. and P. Sardosky (2006), Oil price risk and emerging stock markets, Global Finance Journal, 17, 224-251.

Basher S.A., Haug, A. and P. Sardorsky (2012). Oil price, exchange rates, and emerging stock markets, Energy Economics, 34, 227-240.

Bauwens, L., Laurent, S. and Rombouts, J.V.K. (2006). Multivatiate GARCH models: A survey, Journal of Applied Econometrics, 21, 79-109

Büyükşahin, B., Haigh, M.S. and Robe, M.A. 2008. "Commodities and Equities: A 'Market of One'?”, CFTC Working paper, www.cftc.gov/ucm/groups/public/@aboutcftc /documents/file/amarketofone_update0608.pdf

Chiou, J.S., Lee, Y.H., (2009). Jump dynamics and volatility: oil and the stock markets. Energy 34(6), 788-796.

Choi, K., Hammoudeh, S. (2010). Volatility behavior of oil, industrial commodity and stock markets in a regime-switching environment. Energy Policy 38(8), 4388-4399.

Connolly, R.A., Stivers, C. and Sun, L. (2007). Commonality in the time-variation of stock-stock 
and stock-bond correlations, Journal of Financial Markets, 10(2), 192-218.

Creti, A., Joëts, M., and Mignon, V. (2013) On the links between stock and commodity markets' volatility. Energy Economics 37, 16-28.

Doyle, E., Hill, J., Jack, I. 2007. Growth in commodity investment: Risk and challenges for commodity market participants. Financial Services Authority (FSA) Report. FSA

Engle, R. 2002. Dynamic conditional correlation: A simple class of multivariate generalized autoregressive conditional heteroskedasticity models, Journal of Business and Economic Statistics, 20, 339-350.

Erb, C.B., Harvey, C.R., 2006. The strategic and tactical value of commodity futures. Financial Analysts Journal, March, 69-97.

Fayyad, A., Daly, K., 2011. The impact of oil price shocks on stock market returns: comparing GCC countries with the UK and USA. Emerging Markets Review 12, 61-78.

Filis, G., Degiannakis, S., Floros, C. (2011). Dynamic correlation between stock market and oil prices: The case of oil-importing and oil-exporting countries. International Review of Financial Analysis, 20(3), 152-164.

Frankel, J. A., 2014, Effects of Speculation and Interest Rates in a "Carry Trade" Model of Commodity Prices, Journal of International Money and Finance, forthcoming.

Gilbert, C. L. 2010. How to understand high food prices. Journal of Agricultural Economics, 61, 398-425.

Gorton, G.B., Rouwenhorst, K.G., 2006. Facts and Fantasies about Commodity Futures, Financial Analysts Journal, March, 47-68.

Hafner, C.M., and H. Herwartz, 2006. Volatility Responses for Multivariate GARCH Models: An Exchange Rate Illustration. Journal of International Money and Finance, 25, 719-740.

Hamilton, J.D., 1983. Oil and the macroeconomy since World War II. Journal of Political Economy 9, 228-248.

Hamilton, J.D., 2003. What is an oil shock? Journal of Econometrics 113, 363-398.

Hamilton, J.D., and Wu, J.C., "Effects of Index-Fund Investing on Commodity Futures Prices," Working Paper (May 2012)

Hammoudeh, S. and E. Aleisa (2002), Relationship between spot/futures price of crude oil and equity indices for oil-producing economies and oil-related industries, Arab Economic Journal, 11, 37-62.

Hammoudeh, S., Dibooglu, S., Aleisa, E. (2004). Relationships among U.S. oil prices and oil industry equity indices, International Review of Economics and Finance, 13(4), 427-453.

Huang, R.D., R.W. Masulis and H.R. Stoll (1996), Energy shocks and financial markets, Journal of Futures Markets, 16(1), 1-27.

Jacobsen, B., Marshall, B. R., and Visaltanachoti, N. (2008), Return Predictability Revisited, SSRN working paper, http://papers.ssrn.com/sol3/papers.cfm?abstract_id=1284856.

Jahan-Parvar, M., Vivian, A. and Wohar, M. E. (2012), "Predictability and Underreaction in 
Industry-Level Returns: Evidence from Commodity Markets", SSRN working paper, http://papers.ssrn.com/sol3/papers.cfm?abstract_id=2005365

Jenson, G.R. Johnson, R.R. and Mercer, J.M. (2000), Efficient use of commodity futures in diversified portfolios. Journal of Futures Markets, 20(5), 489-506

Jones, C., and Kaul, G. (1996). Oil and stock markets. Journal of Finance, 51, 463-491.

Lee, B-J., Yang, C., and Huang, B-N. (2012). Oil price movements and stock markets revisited: A case of sector stock price indexes in the G-7 countries, Energy Economics, 34, 12841300.

Ling, S. and McAleer M. (2003), Asymptotic theory for a vector ARMA-GARCH model, Econometric Theory, 19, 278-308.

Maghyereh, A. (2004), Oil price shocks and emerging stock markets: A generalized VAR approach, International Journal of Applied Econometrics and Quantitative Studies, 1(2), 27-40.

Malik, F. and Ewing, B. T. (2009). Volatility transmission between oil prices and equity sector returns, International Review of Financial Analysis, 18, 95-100.

Malik, F. and Hammoudeh, S. (2007). Shock and volatility transmission in the oil, US and Gulf equity markets, International Review of Economics and Finance 16, 357-68.

Mensi, W., Beljid, M., Boubaker, A. And Managi, S. (2013). Correlations and volatility spillovers across commodity and stock markets: Linking energies, food and gold. Economic Modelling 32, 15-22

Mollick, A. and Assefa, T. (2013). U.S. stock returns and oil prices: The tale from daily data and the 2008-2009 financial crisis. Energy Economics, 36, 1-8.

Mouawad, J. (2009). One year after oil's price peak voilatility. New York Times (July 10).

Nazlioglu, S., Erdem, C., Soytas, U., 2013. Volatility spillover between oil and agricultural commodity markets. Energy Economics, 36, 658-665.

Papapetrou, E. (2001), Oil price shocks, stock market, economic activity and employment in Greece. Energy Economics. 23(5), 511-532.

Park, J., Ratti, R.A. (2008). Oil price shocks and stock markets in the US and 13 European countries. Energy Economics. 30, 2587-2608.

Primiceri, G. E., 2005. Time varying structural vector autoregressions and monetary policy. Review of Economic Studies, 72, 821-852.

Ribeiro, R., and Veronesi, P., (2002), The excess comovement of international stock markets in bad times, University of Chicago working paper.

Sadorsky, P. (1999). Oil price shocks and stock market activity. Energy Economics, 21, 449-469.

Sadorsky, P. (2000). The Empirical Relationship Between Energy Futures Prices and Exchange Rates,. Energy Economics, 22, 253-266.

Sadorsky, P. (2004), Stock markets and energy prices, Encyclopedia of Energy, Vol. 5, Elsevier, New York, 707-717. 
Silvennoinen A. and Terasvirta, T. (2009). Multivariate GARCH models, in Handbook of Financial Time Series Part 1 pp 201-229.

Silvennoinen A. and Thorp, S., 2013. Financialization, Crisis and Commodity Correlation Dynamics, Journal of International Financial Markets Institutions and Money, 24, 42-65.

Soros, G., 2008, Bloomberg Article April 17, 2008.

Soucek, M. and Todorova, N. 2013. Realized volatility transmission between crude oil and equity futures markets: A multivariate HAR analysis, Energy Economics, 40, 586-597

Stoll, H.R. and Whaley, R. 2010. Commodity index investing and commodity futures prices. Journal of Applied Finance, 20, 7-46.

Stout, L.A. 2011. "Risk, Speculation, and OTC Derivatives: An Inaugural Essay for Convivium," Accounting, Economics, and Law: Vol. 1: Iss. 1, Article 2.

Tansuchat, R., Chang, C-L., and McAleer, M. 2010. "Conditional Correlations and Volatility Spillovers Between Crude Oil and Stock Index Returns. KIER Discussion Paper, 2010

Valiante, D., 2011, "Commodity Price Formation in Boom-and-Bust Cycles", ECMI Commentaries No. 29, June 2011. http://www.ceps.eu/book/commodity-price-formationboom-and-bust-cycles.

Vivian, A., Wohar, M.E., 2012. Commodity volatility breaks. Journal of International Financial Markets, Institutions, and Money, 22(2), 395-422.

Wang, Y., Wu, C., and Yang, L. (2013). Oil price shocks and stock market activities: Evidence from oil-importing and oil-exporting countries. Journal of Comparative Economics, forthcoming 


\section{Table 1}

Panel A: Mean Equations:

(p-values in Parenthesis)

$$
Y_{t}=\mathbf{c}+\mathbf{A} Y_{\mathrm{t}-1}+\mathbf{B} \text { dollar }_{t-1}+\mathbf{v}_{t}
$$

\begin{tabular}{c|cc}
\hline \hline Variables: & Energy & S\&P 500 \\
\hline \hline $\mathrm{C}$ & 0.12 & 0.26 \\
& $(0.21)$ & $(0.00)$ \\
Energy(t-1) & 0.01 & -0.002 \\
& $(0.63)$ & $(0.80)$ \\
S\&P(t-1) & 0.00 & -0.09 \\
& $(0.98)$ & $(0.00)$ \\
dollar(t-1) & -0.27 & -0.13 \\
& $(0.02)$ & $(0.02)$ \\
& & \\
\hline \hline
\end{tabular}

Panel B: Variance Equations:

$$
\begin{aligned}
& \mathbf{H}(t)=\mathbf{C}^{\prime} \mathbf{C}+\mathbf{A}^{\prime} \mathbf{u}(t-1) \mathbf{u}^{\prime}(t-1) \mathbf{A}+\mathbf{B}^{\prime} \mathbf{H}(t-1) \mathbf{B}+\mathbf{D}^{\prime} \mathbf{d o l l a r}(t-1) \mathbf{D} \\
& \mathbf{C}=\left[\begin{array}{cc}
0.83 & \\
(0.00) & \\
0.10 & 0.38 \\
(0.13) & (0.00)
\end{array}\right] \quad \mathbf{A}=\left[\begin{array}{cc}
0.34 & 0.02 \\
(0.00) & (0.01) \\
-0.06 & 0.32 \\
(0.10) & (0.00)
\end{array}\right] \quad \mathbf{B}=\left[\begin{array}{cc}
0.92 & -0.01 \\
(0.00) & (0.01) \\
0.02 & 0.93 \\
(0.3) & (0.00)
\end{array}\right] \quad \mathbf{D}=\left[\begin{array}{cc}
-0.19 & \\
(0.05) & \\
0.00 & -0.12 \\
(0.96) & (0.12)
\end{array}\right]
\end{aligned}
$$

Panel C: Diagnostic Checks of the Standardized Residuals:

\begin{tabular}{ccccc}
\hline \hline $\begin{array}{c}\text { Ljung-Box } \\
\text { Q-Statistics }\end{array}$ & $\begin{array}{c}\text { Energy } \\
\text { Residuals }\end{array}$ & & \multicolumn{2}{c}{$\begin{array}{c}\text { S\&P 500 } \\
\text { Residuals }\end{array}$} \\
\hline \hline & & Squared & Rquared \\
Lags & Residuals & Residuals & Residuals & $\begin{array}{c}\text { Residuals } \\
\end{array}$ \\
$\mathbf{4}$ & 7.03 & 2.37 & 1.44 & 3.48 \\
& $(0.13)$ & $(0.67)$ & $(0.83)$ & $(0.48)$ \\
$\mathbf{8}$ & 11.14 & 6.27 & 2.24 & 5.80 \\
& $(0.26)$ & $(0.61)$ & $(0.97)$ & $(0.66)$ \\
$\mathbf{1 2}$ & 16.90 & 9.65 & 5.53 & 6.03 \\
& $(0.15)$ & $(0.64)$ & $(0.93)$ & $(0.91)$ \\
$\mathbf{1 6}$ & 22.17 & 17.07 & 11.84 & 9.21 \\
& $(0.13)$ & $(0.32)$ & $(0.75)$ & $(0.90)$ \\
\hline \hline
\end{tabular}


Figure 1: Time Varying Conditional Correlations

Correlations

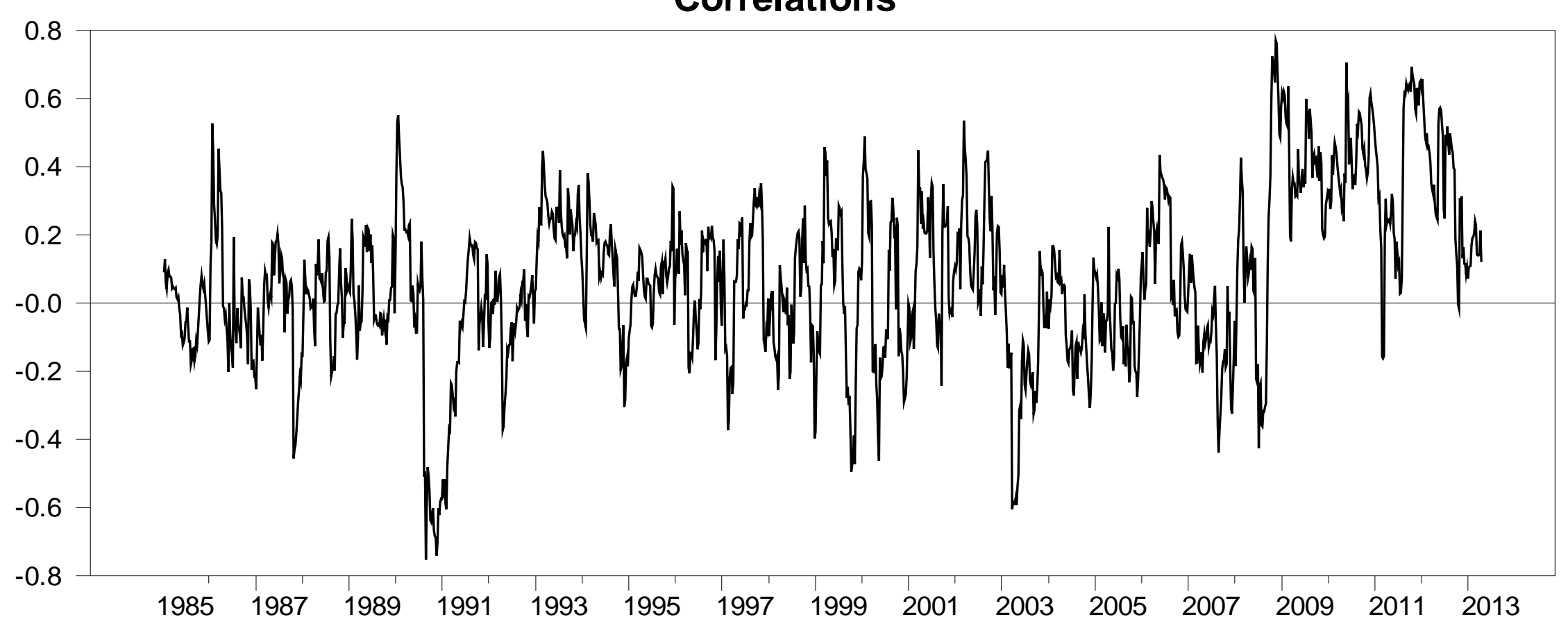


Figure 2: Time Varying Hedge Ratios

Hedge Ratios for S\&P 500

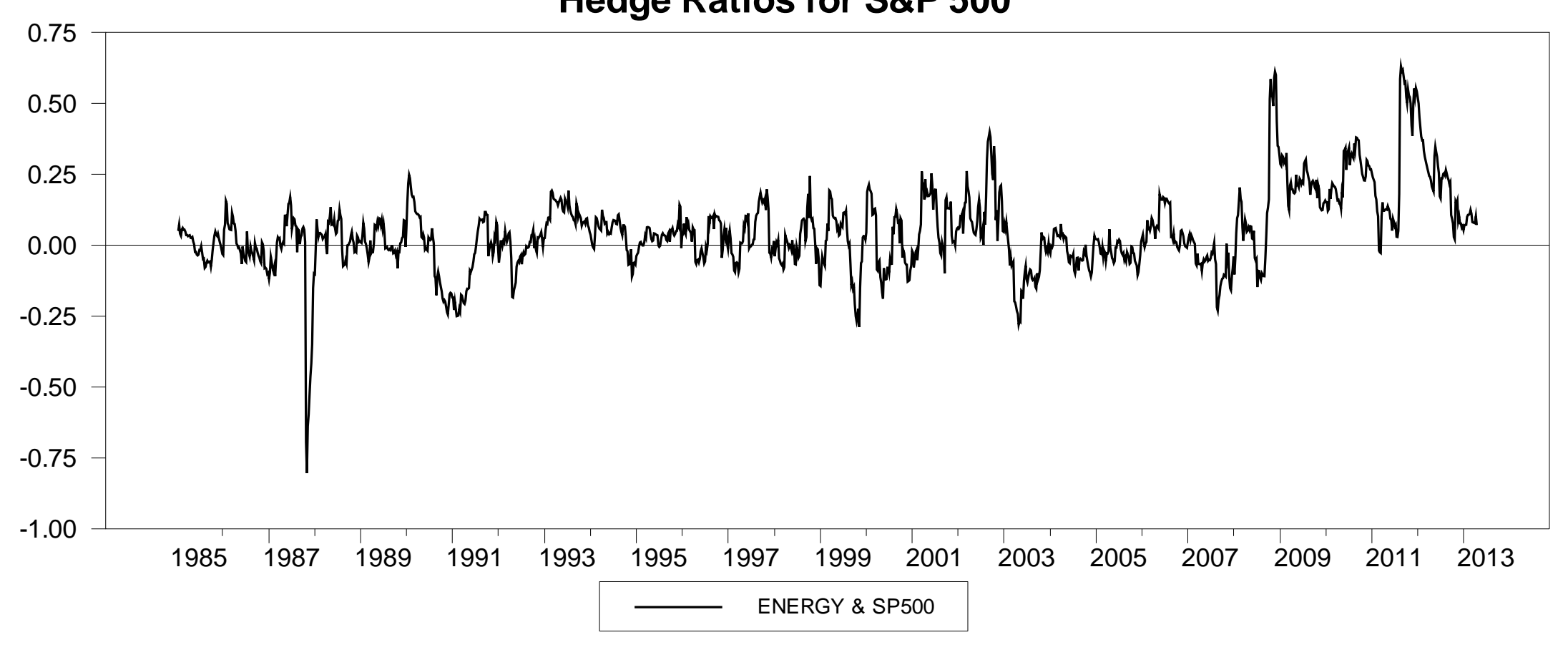


Figure 3: Volatility Impulse Responses (Energy)

5th Percentile
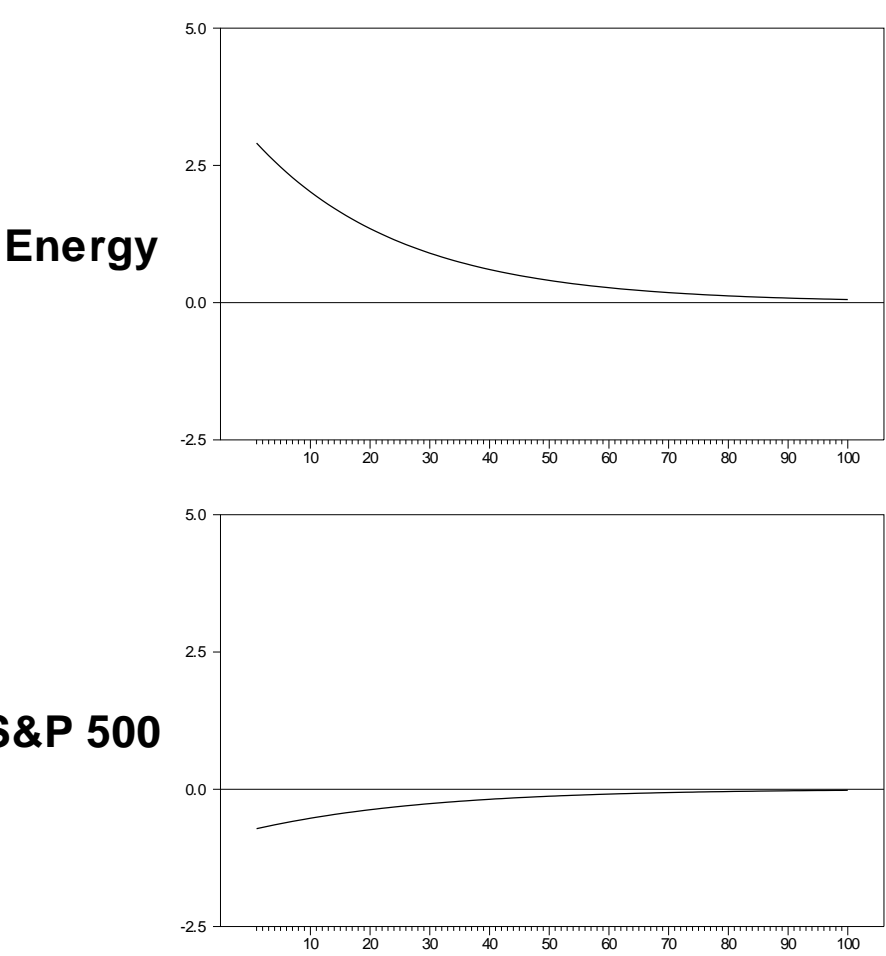

Median
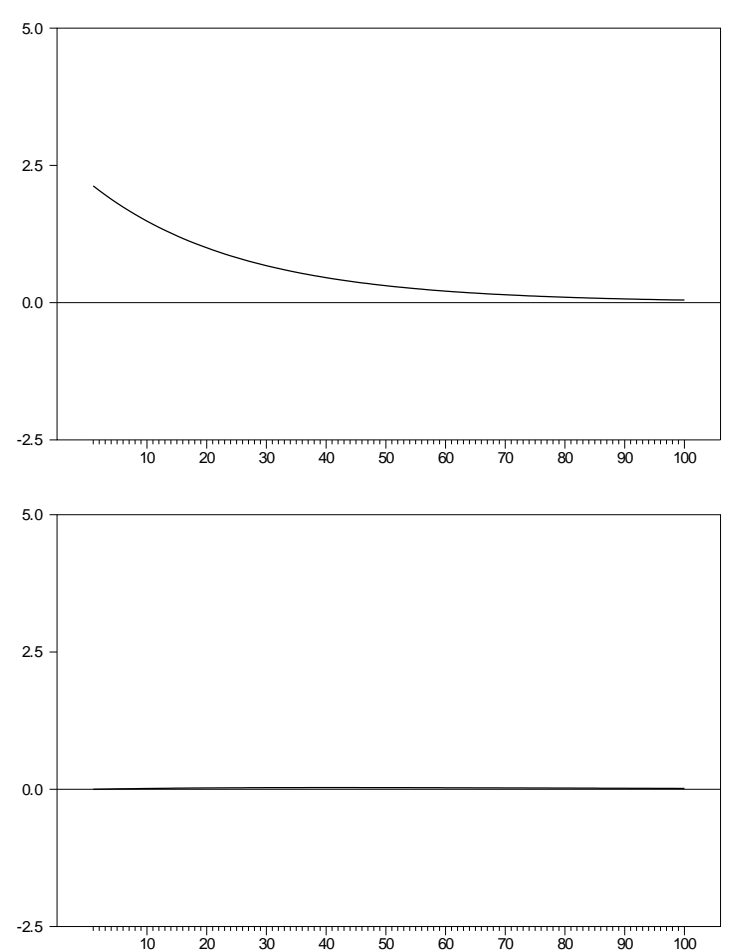

95 Percentile
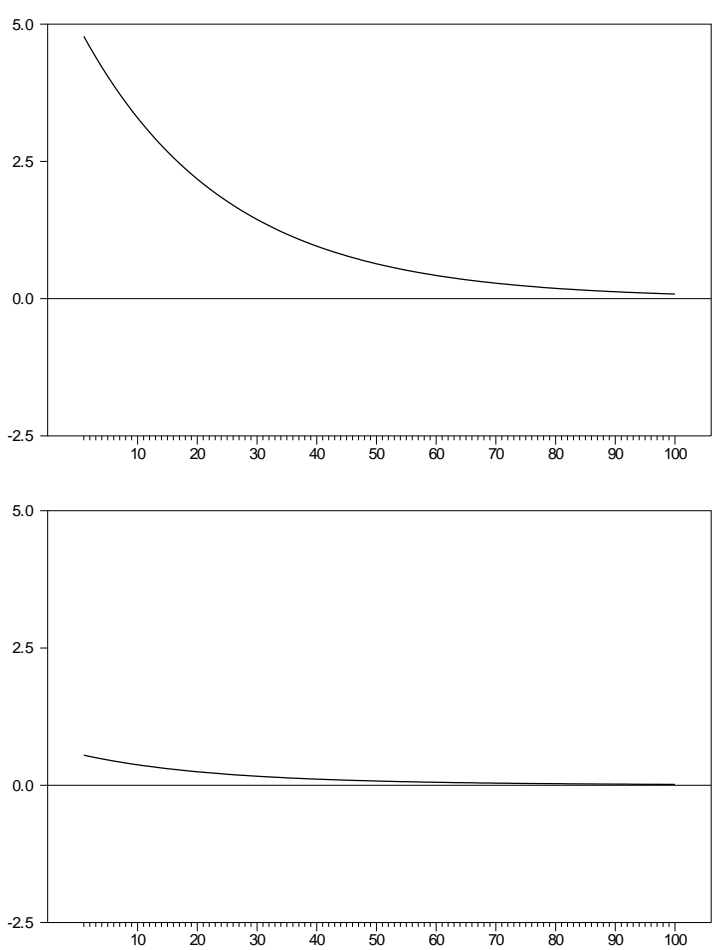

Notes: The $u_{t} u_{t}^{\prime}$ 's used to generate the above volatility impulse response functions were obtained by ordering the energy commodity index and recording the dates which corresponded to the $5^{\text {th }}$ perc., median, and $95^{\text {th }}$ perc. dates of the energy distribution. The $u_{t} u_{t}^{\prime}$ 's from the estimated BEKK model were then selected according to the recorded dates. The 0.0 benchmark is the expected conditional variance. Shocks eventually return to their expected conditional variance following a shock. 
Figure 4: Volatility Impulse Responses (S\&P 500)

5th Percentile

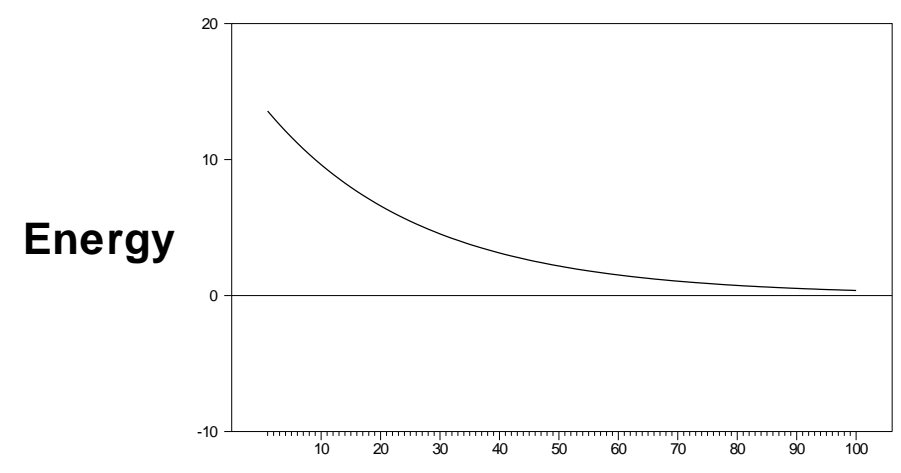

S\&P 500

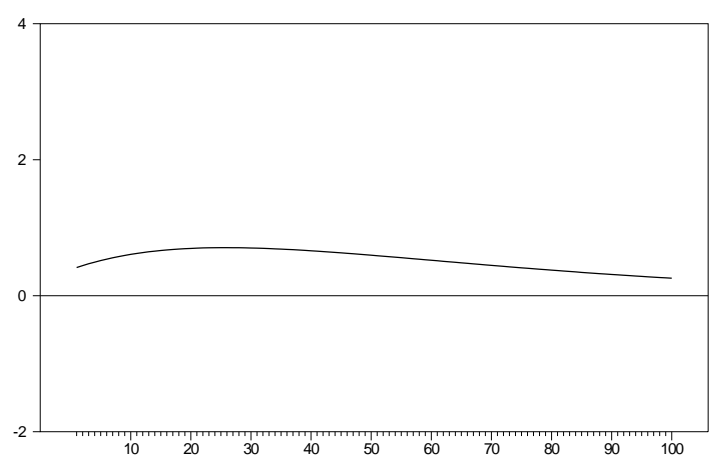

Median
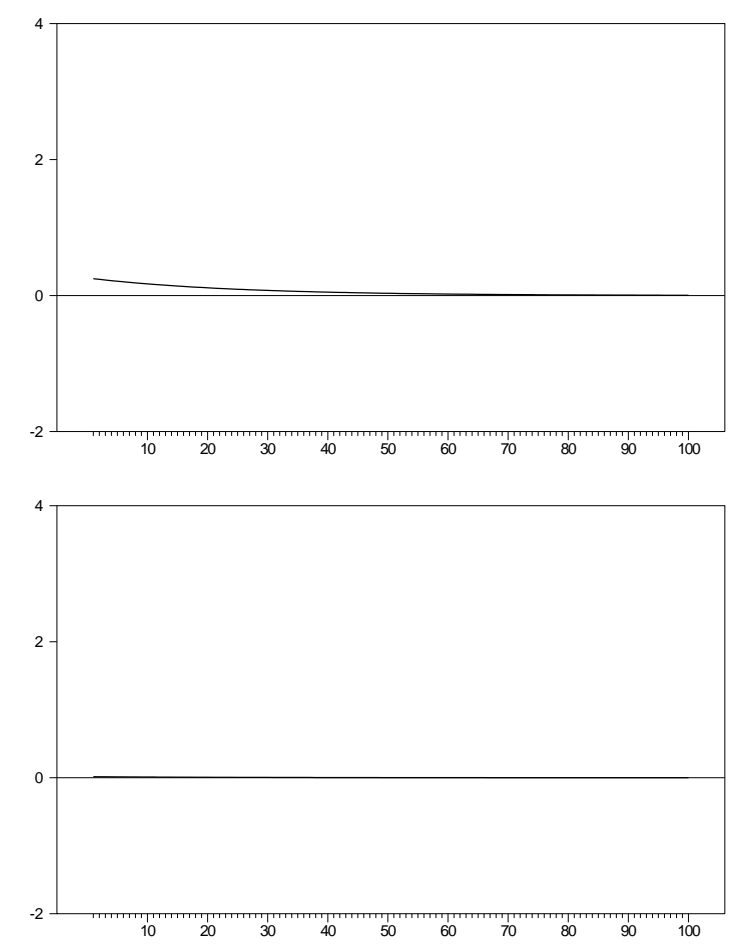

95 Percentile
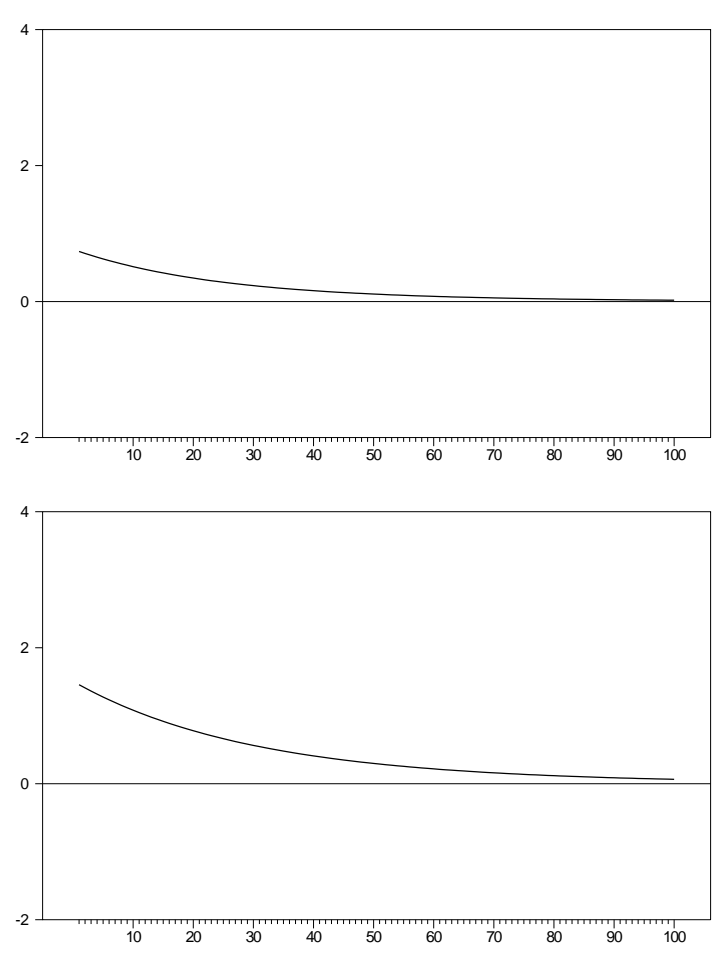

Notes: The $u_{t} u_{t}^{\prime}$ 's used to generate the above volatility impulse response functions were obtained by ordering the S\&P 500 and recording the dates which corresponded to the $5^{\text {th }}$ perc., median, and $95^{\text {th }}$ perc. of the energy distribution. The $u_{t} u_{t}^{\prime}$ 's from the estimated BEKK model were then selected according to the recorded dates. The 0.0 benchmark is the expected conditional variance. Shocks eventually return to their expected conditional variance following a shock. 